\title{
EDUCATION AND HUMAN DEVELOPMENT
}

\section{Effortful Control in Primary Schoolchildren: Links with Personality, Problem Behaviour, Academic Achievement, and Subjective Well-Being}

\author{
Olga S. Kornienko ${ }^{a, b^{*}}$, Evgeniya N. Petrenko ${ }^{a}$, Irina V. Leto ${ }^{a}$, \\ Natalija A. Fedorova ${ }^{c}$, and Helena R. Slobodskaya ${ }^{a, b}$ \\ ${ }^{a}$ Institute of Physiology and Basic Medicine, Novosibirsk, Russia \\ ${ }^{b}$ Novosibirsk State University, Novosibirsk, Russia \\ ${ }^{c}$ Geraskov Children's Clinical Hospital No. 4, Novosibirsk, Russia \\ *Corresponding author. E-mail: olfa@mail.ru
}

Background: Effortful control is a core aspect of self-regulation and refers to the ability to voluntarily regulate behaviour and attention, measured by temperament questionnaires. Although the Temperament in Middle Childhood Questionnaire is widely used in different countries, this measure has not been fully explored. Most research on the links of effortful control with personality and important outcomes has been carried out in Western nations; the possibility of extending these findings to other cultures requires study.

Objective: To examine effortful control and its relations to personality and wellbeing in a community sample of primary schoolchildren in Russia.

Design: Parents of 7-10-year-olds $(\mathrm{N}=614)$ completed the abbreviated Effortful Control scale of the TMCQ, the Inventory of Child Individual Differences-Short version, and the Strengths and Difficulties Questionnaire (SDQ); teachers provided SDQ data and school grades; children completed the Students' Life Satisfaction Scale.

Results: The findings supported a four-factor structure of Effortful Control, including Attention Focusing, Inhibitory Control, Activation Control, and Low-Intensity Pleasure. Effortful Control was associated with the personality traits of Conscientiousness, Agreeableness, and Openness, and also with Positive Emotions and low Neuroticism. Effortful Control was also associated with academic achievement, subjective well-being, and lower levels of externalising and internalising problems. Structural modelling showed that Attentional Control contributed to problem behaviour and subjective wellbeing; Inhibitory Control contributed to externalising problems; and Activation Control contributed to academic achievement. 
Conclusion: Effortful Control and its components were strongly related to higherand lower-order personality traits. The findings confirmed the important role of effortful control in the academic success and well-being of Russian primary schoolchildren.

Keywords: effortful control, middle childhood, personality, well-being, problem behaviour, academic achievement, life satisfaction

\section{Introduction}

Effortful control is an integral part of temperament in children, together with Negative Affectivity and Positive Affectivity. It refers to the ability to choose a course of action under conditions of internal conflict, to detect errors, and to plan (Rothbart, 2007). Effortful control is also defined as the ability to voluntarily regulate behaviour and attention, as seen in the inhibition of a dominant response and activation of a subdominant response (Rothbart, Ahadi, \& Evans, 2000). This construct emerged initially from psychometric studies of parent reports (Rothbart, 2007), showing that effortful control develops throughout the early years along with the maturation of attentional and inhibitory mechanisms (Rothbart, Sheese, Rueda, \& Posner, 2011). Factor-analytic studies provided evidence that the content of the Effortful Control factor is largely similar across ages; the differences mostly reflect changes in the behavioural repertoire (Putnam, Ellis, \& Rothbart, 2001). In all ages after early childhood, effortful control includes traits reflecting the capacity to focus and to shift attention, and the inhibitory control trait, reflecting an ability to suppress inappropriate actions or responses. In children, but not in adolescents and adults, effortful control includes the trait of low-intensity pleasure, reflecting enjoyment related to low stimulus intensity, rate, novelty, and incongruity; and the perceptual sensitivity trait, which encompasses the detection of subtle stimuli from the external environment. Activation control, reflecting the capacity to perform an action when there is a strong tendency to avoid it, is included in the effortful control measure from middle childhood onwards.

Effortful Control in middle childhood includes five components - Attention Focusing, Inhibitory Control, Activation Control, Low-Intensity Pleasure, and Perceptual Sensitivity - measured by the Temperament in Middle Childhood Questionnaire (TMCQ, Simonds, Kieras, Rueda, \& Rothbart, 2007; Simonds \& Rothbart, 2004). Although the TMCQ is widely used in different countries, this measure has not been fully explored, and has dubious psychometric properties. A recent study of a large sample of 9-year-old North American children (Kotelnikova, Olino, Klein, Mackrell, \& Hayden, 2016) demonstrated that the structure of the TMCQ differed from the original three-factor model developed by Rothbart and colleagues (Rothbart, 2007; Rothbart et al., 2000); it also showed that Effortful Control items did not form five facets as posited by Simonds and Rothbart (2004). Thus, the structure of Effortful Control in middle childhood requires further investigation.

The first aim of this study was to investigate the psychometric properties of the Russian version of the TMCQ Effortful Control scale. We examined the structure of Effortful Control in primary schoolchildren, and also whether gender and effects in the Russian cultural context are similar to those found in other cultures. A meta-analysis of gender differences in child temperament revealed a 
large difference in effortful control favouring girls and moderate differences in inhibitory control and perceptual sensitivity (Else-Quest, Hyde, Goldsmith, \& Van Hulle, 2006). Because most evidence on the development of effortful control comes from experimental studies of attention and inhibitory control (Rothbart et al., 2011), our analysis of age differences in parent-report measures was primarily exploratory.

Traditionally, research on individual differences has conceptualized childhood traits as temperament, and adult traits as personality. Work with parental and teacher descriptions of children during recent decades has demonstrated the robustness of the Five Factor Theory of personality development (Caspi \& Shiner, 2006; Halverson et al., 2003; Kohnstamm, Halverson, Mervielde, \& Havill, 1998). It has been also recognized that both temperament and personality traits are manifestations of the same basic dimensions (Caspi \& Shiner, 2006; Shiner \& DeYoung, 2013). For example, Digman and Shmelyov (1996) demonstrated the structural similarity of temperament and the Big Five personality factors in a sample of Russian primary schoolchildren. Self-regulatory behaviours encompassed by effortful control are consistently related to the personality domain of Conscientiousness (Halverson et al., 2003; Shiner \& DeYoung, 2013). Effortful control is also related to the domain of Agreeableness, which reflects self-regulation in positive social interactions (Caspi \& Shiner, 2006). However, little is known about how different aspects of effortful control relate to higher- and lower-order personality traits. Therefore, our second aim was to examine the relationships of effortful control and its components with personality in middle childhood.

The biological basis of temperament and personality appear to be shared across cultures, but outcomes may vary depending on cultural context and personal experience (Rothbart, 2007). There is increasing evidence that children's effortful control predicts important life outcomes. In middle childhood, these include problem behaviours, academic achievement, and life satisfaction, which are also considered to be core domains of child well-being (O'Hare \& Gutierrez, 2012; Rees et al., 2012). In childhood, problem behaviours are widespread; they may interfere with everyday life and prevent children from accomplishing important developmental tasks. Research has shown that most childhood problems fall into two main groups: The behavioural or externalising problems include destructiveness, aggression, hyperactivity, and antisocial behaviours; the emotional or internalising problems involve worries, fears, depressive features, and psychosomatic symptoms (Goodman \& Scott, 2012). Many studies have established strong links between a lack of effortful control and children's problem behaviour; links with externalising problems tend to be stronger than those with internalising problems (Rothbart, 2007).

There is consistent evidence that children's effortful control is associated with academic outcomes such as self-regulated learning and mathematics and literacy skills (Eisenberg, Valiente, \& Eggum, 2010). Academic trajectories tend to be established early in preschool or elementary school (McClelland, Acock, \& Morrison, 2006), and the transition from preschool to elementary school poses greater demands for effortful control, requiring children to focus their attention for a longer time, to inhibit inappropriate behaviour in class, and to do home- 
work. However, only a few studies have examined the contribution of different components of effortful control to academic achievement (Oberle \& SchonertReichl, 2013; Sánchez-Pérez, Fuentes, Pina, López-López, \& González-Salinas, 2015).

A longitudinal study of a cohort of 1,000 people from birth to age 32 showed that childhood self-control predicts physical and mental health, as well as life satisfaction in adulthood (Moffitt et al., 2011; Moffitt, Poulton, \& Caspi, 2013). Life satisfaction, a term which is often used interchangeably with subjective well-being and happiness, is a subjective evaluation of overall quality of life (Proctor, Linley, \& Maltby, 2009). While early research on child development was largely focused on important outcomes and children's quality of life from an adult perspective, contemporary studies emphasize the importance of measuring children's subjective well-being and/or life satisfaction (Rees et al., 2012). However, very little is known about the association between effortful control and subjective well-being in childhood.

Most research on the links between effortful control and important life outcomes has been carried out in Western nations; the possibility of extending these findings to other cultures requires study. Therefore, the third aim of this study was to examine the relations between effortful control and well-being, including problem behaviour, subjective well-being, and academic achievement, in a community sample of Russian primary schoolchildren. Because in Russia formal schooling typically starts around age 7, this study focuses on middle childhood (7-10 years). Drawing on prior research, we anticipated significant associations between a lack of effortful control and problem behaviour, specifically with externalising problems. We expected that effortful control would be related to academic achievement in primary school, although a priori predictions regarding components of effortful control could not be specified, since the results of previous studies have been inconclusive. Addressing the links between effortful control and children's subjective well-being, our study was largely exploratory.

\section{Method}

\section{Participants and Procedures}

The sample consisted of 614 children from 7 to 10 years old (55\% female); the average age was $8.6(S D=1.1)$. Participants were from two Siberian cities, Novosibirsk (65\%) and Novokuznetsk (28\%), and from nearby rural regions. Most of the children (68\%) lived with both biological parents, $20 \%$ with a single mother, $10 \%$ with a mother and a stepfather, and the rest with other caregivers; $53 \%$ had one or more siblings. Regarding education, $8 \%$ of the mothers and $12 \%$ of the fathers had 10 years of schooling or less; $27 \%$ of the mothers and $29 \%$ of the fathers had secondary vocational education; $65 \%$ of the mothers and $59 \%$ of the fathers had university education. Twenty-two percent of the mothers and $36 \%$ of the fathers were unskilled or manual workers; $48 \%$ of the mothers and $35 \%$ of the fathers had professional occupations; and $13 \%$ of the mothers and $26 \%$ of the fathers had administrative occupations. Seventeen percent of the mothers and 3\% of the fathers were unemployed. 
Participants were recruited through schools, social websites, and in person. Parents were asked to complete the Inventory of Child Individual Differences (ICID), the Strengths and Difficulties Questionnaire (SDQ), the Effortful Control (EC) scale, and a brief demographic questionnaire. Parents of 69 children also completed the EC scale 12 months later. Teachers completed the SDQ and provided information on school grades for 437 children. The Students' Life Satisfaction Scale was completed by 330 children. All questionnaires were administered as paper and pencil instruments. Informed consent was obtained from all individual participants included in the study.

\section{Measures}

Effortful Control. The Effortful Control scale of the Temperament in Middle Childhood Questionnaire (TMCQ, Simonds et al., 2007; Simonds \& Rothbart, 2004) consists of 48 items relating to five subscales. These include Activation Control (example items: "Has a hard time working on an assignment s/he finds boring" (reversed scored) and "Can make him/herself do homework, even when s/he wants to play"), Attention Focusing (example items: "Needs to be told to pay attention" and "Is easily distracted when listening to a story", both reversed scored), Inhibitory Control (example items: "Can stop him/herself from doing things too quickly" and "Has an easy time waiting to open a present"), Low-Intensity Pleasure (example items: "Enjoys looking at books" and "Likes the sound of poems"), and Perceptual Sensitivity (example items: "Notices things others don't notice" and "Notices when parents are wearing new clothing"). Parents were asked to rate their child, using a 5-point scale ranging from "almost always untrue of your child" to "almost always true of your child", with an additional option of "not applicable". More information about TMCQ is available on Mary Rothbart's Temperament Questionnaires website. We deleted items related to situations where parents were often absent, such as child behaviour in class (e.g., "Needs to be told by the teacher to pay attention") and with peers (e.g., "Can apologize or shake hands after a fight"). The remaining 19 items were translated from English to Russian and subsequently back-translated. The original and the back-translated copies were compared, and the Russian translation was revised on the basis of the observed discrepancies.

Personality. The Inventory of Child Individual Differences-Short version (ICID-S; Slobodskaya \& Zupančič, 2010) is an age- and culture-decentred measure of child personality. The ICID-S includes 62 items rated on a 7-point scale ranging from "much less than the average child" to "much more than the average child". The items represent 15 mid-level traits that form the five higher-order factors. Extraversion is comprised of the scales Activity, Positive Emotions, and Sociable. Disagreeableness includes Antagonism, Strong Willed, and reversed Considerate. Conscientiousness is comprised of Achievement, Compliant, Organized, and reversed Distractible. Neuroticism includes Fearful, Shy, and Negative Affect. Openness is comprised of Intelligent and Open to Experience. The Russian version has been validated, supporting good reliability of the scales (Slobodskaya \& Zupančič, 2010). In the present study, alphas for five higher-order ICID-S scales ranged from 
.83 to .90 with a mean of .86 ; alphas for 15 mid-level ICID-S scales ranged from .73 to .85 with a mean of .79 .

Problem behaviour. The Strengths and Difficulties Questionnaire (SDQ, Goodman, 2001) is a widely used measure for assessing common emotional and behavioural problems in children. The SDQ 20 items on difficulties are divided into four scales: Emotional Symptoms, Peer Problems, Conduct Problems, and Hyperactivity; all are summed to generate a Total Difficulties score. Each subscale consists of five statements, which describe the characteristic behaviour of the child in the last six months. Respondents marked each statement as "not true", "somewhat true", or "certainly true". The Internalising Problems scale includes Emotional Symptoms and Peer Problems; the Externalising Problems scale includes Conduct Problems and Hyperactivity. The Russian version has been validated in a stratified random sample (Goodman, Slobodskaya, \& Knyazev, 2005). In the present study, we used parent- and teacher-versions of the SDQ, because information from more than one source can help to obtain more robust findings. Alphas for the SDQ scales ranged from .68 to .88 .

Academic achievement. Academic achievement was evaluated by an internationally recognized measure, grade point average (GPA), the mean of the Russian, math, and literature grades for the year. These three disciplines are core academic subjects in primary school. It should be noted that the restricted range of grades is a limitation, however, high internal consistency reliability $(\alpha=.85)$ provides justification for its use.

Subjective well-being. Subjective child well-being was evaluated by the Russian version of the Students' Life Satisfaction Scale (SLSS, Huebner, 1991), which consists of seven statements rated on a 6-point scale ranging from "strongly disagree" to "strongly agree". The statements are overall evaluations of the young person's life, for example: "My life is going well". The Russian version has been validated, supporting good reliability of the scale (Leto, Petrenko, \& Slobodskaya, 2018). In the present study, alpha was .74 .

\section{Results}

\section{Structure of the Effortful Control Scale}

We tested an a priori five-factor structure of Effortful Control using confirmatory factor analysis with AMOS 17.0 software (Arbuckle, 2008). This model did not, however, show acceptable fit: $\chi^{2}=479.6, d f=141, p<.001, \mathrm{CFI}=.74$, RM$\mathrm{SEA}=.074$. An examination of factor loadings and modification indices led to the exclusion of the Perceptual Sensitivity subscale; one item was deleted from the Inhibitory Control subscale and two items from the Activation Control subscale. The final model of Effortful Control (EC) comprised four latent variables - Attention Focusing (AF), Inhibitory Control (IC), Activation Control (AC), and Low-Intensity Pleasure (LIP) - with one additional cross-loading of Item 5, "Can make him/herself do homework, even when s/he wants to play" on the IC factor (Figure 1). 


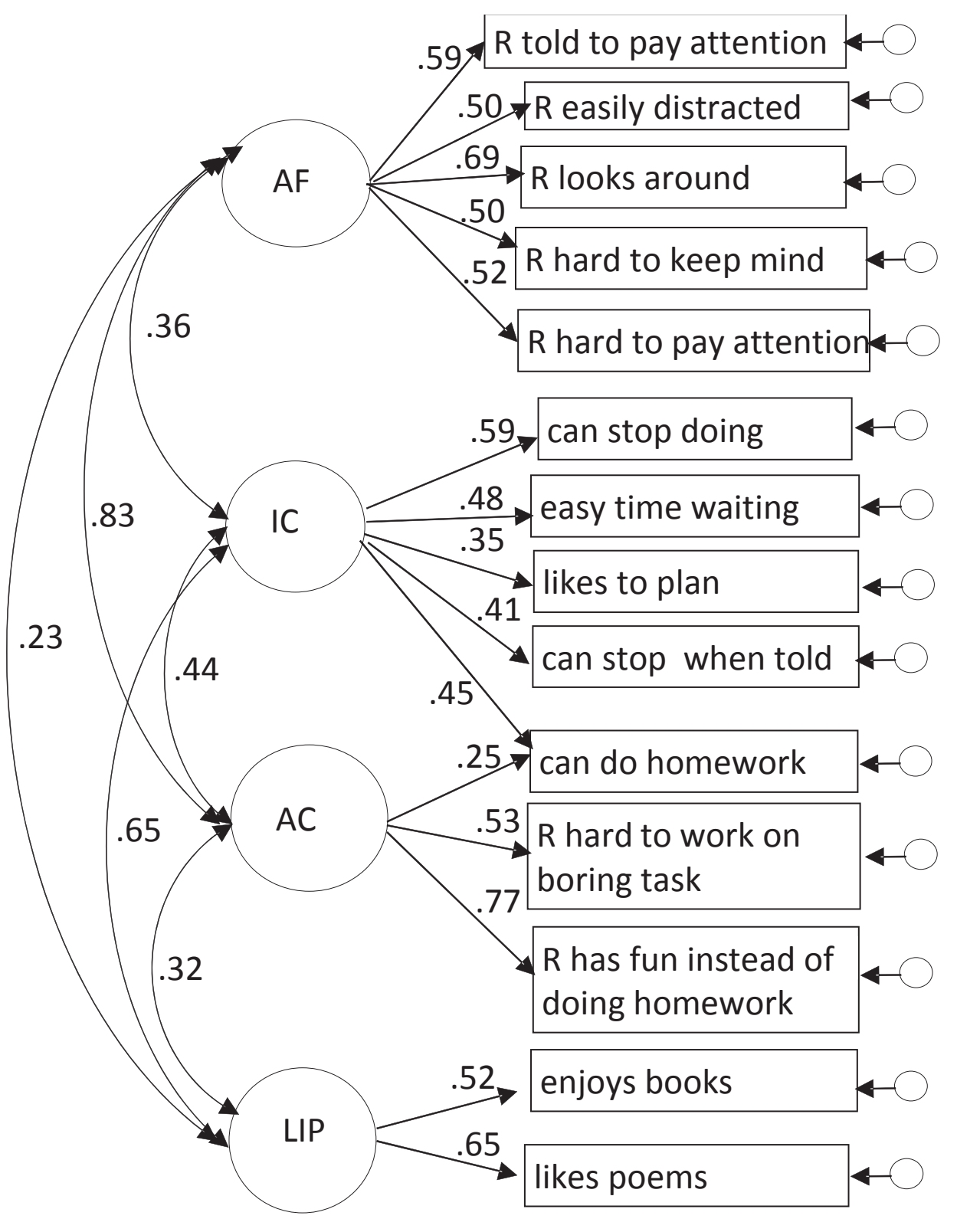

Figure 1. Structural model of the Effortful Control scale in Russian primary schoolchildren $(\mathrm{N}=614)$.

Note. Values are standardised parameter estimates. AF - Attention Focusing, IC - Inhibitory Control, AC - Activation Control, LIP - Low-Intensity Pleasure. R = reversed.

The fit of the final model was satisfactory: $\chi^{2}=178.65, d f=70, p<.001$, $\mathrm{CFI}=.919$, RMSEA $=.050$. Cronbach's alpha coefficients for the 14-item EC scale and four subscales, AF, IC, AC, and LIP, were .76, .70, .59, .60 and .50, respectively. One-year test-retest correlations, obtained for 69 children whose parents completed the Effortful Control scale one year later, were $.56, .45, .44$ and .64 for EC, AF, IC and LIP, respectively; all $p s<.001$, and $r=.40$ for AC, $p<.01$.

To assess the effect of demographic variables, 2 (gender) $\times 4$ (ages $7,8,9$, and 10) analyses of variance were performed. The effect size was estimated by eta 
Table 1

Descriptive Statistics and Gender Differences for Effortful Control Measures

\begin{tabular}{|c|c|c|c|c|c|}
\hline & $\begin{array}{c}\text { Total sample } \\
(N=614)\end{array}$ & $\begin{array}{c}\text { Girls } \\
(N=338)\end{array}$ & $\begin{array}{c}\text { Boys } \\
(N=276)\end{array}$ & & \\
\hline & $M(S D)$ & $M(S D)$ & $M(S D)$ & $F^{\mathrm{a}}$ & $\eta^{2}$ \\
\hline Effortful Control & $\begin{array}{l}3.18 \\
(.55)\end{array}$ & $\begin{array}{l}3.26 \\
(.54)\end{array}$ & $\begin{array}{l}3.09 \\
(.55)\end{array}$ & $15.47^{\star \star \star}$ & .025 \\
\hline Attention Focusing & $\begin{array}{l}2.97 \\
(.75)\end{array}$ & $\begin{array}{l}3.06 \\
(.74)\end{array}$ & $\begin{array}{l}2.86 \\
(.75)\end{array}$ & $10.65^{\star * *}$ & .017 \\
\hline Inhibitory Control & $\begin{array}{l}3.34 \\
(.71)\end{array}$ & $\begin{array}{l}3.37 \\
(.67)\end{array}$ & $\begin{array}{l}3.31 \\
(.74)\end{array}$ & 1.03 & .002 \\
\hline Activation Control & $\begin{array}{l}3.06 \\
(.84)\end{array}$ & $\begin{array}{l}3.16 \\
(.81)\end{array}$ & $\begin{array}{l}2.94 \\
(.87)\end{array}$ & $10.44^{\star *}$ & .017 \\
\hline Low-Intensity Pleasure & $\begin{array}{l}3.72 \\
(.96)\end{array}$ & $\begin{array}{l}3.86 \\
(.93)\end{array}$ & $\begin{array}{l}3.54 \\
(.97)\end{array}$ & $18.06^{\star \star \star}$ & .029 \\
\hline
\end{tabular}

Note. ${ }^{a}$ Degrees of freedom were $(1,613) .{ }^{* *} p<.01 ;{ }^{* *} p<.001$.

squared $\left(\eta^{2}\right)$. Results showed that age effect and gender-by-age interactions were not significant. Table 1 shows descriptive statistics along with gender differences. Gender differences were significant for the Effortful Control scale and all subscales except Inhibitory Control, with girls scoring higher than boys. Gender effects accounted for $2.5 \%$ of the variance or less.

\section{Relations Between Effortful Control and Personality Traits}

Table 2 shows the correlation coefficients between Effortful Control and personality traits. Effortful Control and its subscales had high to medium positive associations with the Conscientiousness domain. Negative correlations with the Disagreeableness domain were medium, whereas negative correlations with the Neuroticism domain were of low to medium magnitude. Effortful Control and its subscales were positively correlated with the Openness domain; correlations with the trait Intelligent were mostly higher than those with trait Open to Experience. The correlations between Effortful Control and traits from the Extraversion domain were mostly insignificant; however, the trait of Positive Emotions had low to medium correlations with Effortful Control and its subscales.

\section{Relationship of Effortful Control to Problem Behaviour, Academic Achievement, and Subjective Well-Being}

Table 3 shows bivariate relationships between parent-reported effortful control and problem behaviours reported by parents and teachers. All significant correlations were negative; for both parent and teacher reports, correlations for externalising problems were higher than for internalising problems. Correlations of Effortful Control measures with teacher SDQ scales were lower than those with parent SDQ 
Table 2

Correlations Between the Effortful Control and ICID-S Scales

\begin{tabular}{lccccc}
\hline & EC & AF & IC & AC & LIP \\
\cline { 2 - 6 } Extraversion & .04 & -.00 & .00 & .10 & .07 \\
Activity & -.09 & -.11 & -.06 & .02 & -.03 \\
Sociable & .01 & -.02 & -.02 & .06 & .04 \\
Positive emotions & .18 & .13 & .09 & .15 & .18 \\
Disagreeableness & -.38 & -.26 & -.28 & -.36 & -.21 \\
Considerate & .23 & .14 & .18 & .20 & .19 \\
Antagonism & -.33 & -.24 & -.24 & -.30 & -.16 \\
Strong Willed & -.36 & -.25 & -.26 & -.36 & -.16 \\
Conscientiousness & .62 & .49 & .47 & .51 & .24 \\
Achievement & .54 & .39 & .44 & .46 & .22 \\
Organized & .53 & .40 & .41 & .45 & .21 \\
Compliant & .48 & .35 & .39 & .38 & .21 \\
Distractible & -.55 & -.52 & -.32 & -.44 & -.17 \\
Neuroticism & -.26 & -.20 & -.16 & -.29 & -.09 \\
Fearful & -.14 & -.13 & -.07 & -.17 & -.01 \\
Shy & -.11 & -.12 & -.00 & -.18 & -.02 \\
Negative Affect & -.30 & -.19 & -.26 & -.27 & -.16 \\
Openness & .32 & .29 & .16 & .26 & .20 \\
Open to experience & .18 & .14 & .09 & .12 & .19 \\
Intelligent & .37 & .36 & .18 & .34 & .17 \\
\hline
\end{tabular}

Note. EC - Effortful Control, AF - Attention Focusing, IC - Inhibitory Control, AC - Activation Control, LIP - Low-Intensity Pleasure. All correlations greater than $|.15|$ are significant at $p<.001$; correlations greater than $|.09|$ are significant at $p<.05$; correlations greater than $|.40|$ are in bold; nonsignificant correlations are in italics.

scales. Table 3 also shows that, with the exception of Inhibitory Control, all Effortful Control measures were positively correlated with children's subjective wellbeing and academic achievement.

Next, we tested structural models in which effortful control was expected to predict child well-being as indexed by the latent constructs of problem behaviour, academic achievement, and subjective well-being. We used structural equation modelling (SEM) because this approach allowed us to explore several outcomes simultaneously. Given that each child at the same time has distinct levels of academic achievement, subjective well-being, and problem behaviour, it would be most appropriate to analyse the contribution of effortful control to these components of child well-being in the same model. In addition, the advantage of SEM is that it estimates how well the model fits the empirical data. 
Table 3

Correlations Between Effortful Control and Well-Being

\begin{tabular}{|c|c|c|c|c|c|}
\hline SDQ scales ${ }^{\mathrm{a}}$ & EC & $\mathrm{AF}$ & IC & $\mathrm{AC}$ & LIP \\
\hline Internalising Problems & $\begin{array}{l}-.28^{* * *} \\
\left(-.11^{\star}\right)\end{array}$ & $\begin{array}{l}-.30^{\star * *} \\
\left(-.12^{\star}\right)\end{array}$ & $\begin{array}{c}-.15^{* * *} \\
(-.01)\end{array}$ & $\begin{array}{l}-.27^{* * *} \\
\left(-.13^{\star *}\right)\end{array}$ & $\begin{array}{l}-.03 \\
(-.02)\end{array}$ \\
\hline Emotional Problems & $\begin{array}{c}-.30^{* * *} \\
(-.09)\end{array}$ & $\begin{array}{l}-.33^{\star * *} \\
\left(-.12^{\star *}\right)\end{array}$ & $\begin{array}{l}-.15^{\star * *} \\
(-.03)\end{array}$ & $\begin{array}{l}-.25^{\star * *} \\
(-.08)\end{array}$ & $\begin{array}{l}-.06 \\
(.01)\end{array}$ \\
\hline Peer Problems & $\begin{array}{c}-.17^{* * *} \\
(-.09)\end{array}$ & $\begin{array}{c}-.16^{* * *} \\
(-.08)\end{array}$ & $\begin{array}{c}-.10^{*} \\
(.01)\end{array}$ & $\begin{array}{l}-.20^{\star * *} \\
\left(-.14^{\star *}\right)\end{array}$ & $\begin{array}{c}.01 \\
(-.05)\end{array}$ \\
\hline Externalising Problems & $\begin{array}{c}-.65^{\star \star \star} \\
\left(-.31^{\star * \star}\right)\end{array}$ & $\begin{array}{c}-.53^{\star * \star} \\
\left(-.29^{\star * \star}\right)\end{array}$ & $\begin{array}{c}-.50^{\star * \star} \\
\left(-.18^{\star * \star}\right)\end{array}$ & $\begin{array}{c}-.50^{\star * \star} \\
\left(-.27^{\star * \star}\right)\end{array}$ & $\begin{array}{l}-.23^{\star * *} \\
\left(-.11^{\star}\right)\end{array}$ \\
\hline Conduct Problems & $\begin{array}{c}-.43^{\star * \star} \\
\left(-.20^{\star * *}\right)\end{array}$ & $\begin{array}{c}-.31^{\star * *} \\
\left(-.17^{\star * *}\right)\end{array}$ & $\begin{array}{c}-.35^{\star * *} \\
\left(-.11^{\star}\right)\end{array}$ & $\begin{array}{c}-.36^{\star * *} \\
\left(-.17^{\star * *}\right)\end{array}$ & $\begin{array}{c}-.19^{* * *} \\
(-.09)\end{array}$ \\
\hline Hyperactivity-Inattention & $\begin{array}{l}-.64^{\star * *} \\
\left(-.34^{\star * *}\right)\end{array}$ & $\begin{array}{l}-.54^{\star * *} \\
\left(-.32^{\star * *}\right)\end{array}$ & $\begin{array}{l}-.48^{* * *} \\
\left(-.20^{* * *}\right)\end{array}$ & $\begin{array}{l}-.48^{* \star *} \\
\left(-.29^{\star * *}\right)\end{array}$ & $\begin{array}{l}-.21^{* * *} \\
\left(-.10^{*}\right)\end{array}$ \\
\hline Total Difficulties & $\begin{array}{l}-.57^{\star \star \star} \\
\left(-.26^{\star \star \star}\right)\end{array}$ & $\begin{array}{l}-.50^{\star * *} \\
\left(-.26^{\star * *}\right)\end{array}$ & $\begin{array}{l}-.40^{\star * *} \\
\left(-.13^{\star *}\right)\end{array}$ & $\begin{array}{l}-.47^{\star * *} \\
\left(-.25^{\star * *}\right)\end{array}$ & $\begin{array}{c}-.16^{* * *} \\
(-.08)\end{array}$ \\
\hline Grade point average & $.28^{\star * *}$ & $.29^{* * *}$ & .09 & $.30^{* * *}$ & $.12^{*}$ \\
\hline Subjective well-being & $.18^{\star *}$ & $.24^{\star * *}$ & .04 & $.18^{\star *}$ & .03 \\
\hline
\end{tabular}

Note. EC - Effortful Control, AF - Attention Focusing, IC - Inhibitory Control, AC - Activation Control, LIP - Low-Intensity Pleasure. ${ }^{a}$ Parent-ratings, teacher-ratings (in parenthesis). ${ }^{*} p<.05$; ${ }^{* *} p<.01 ;{ }^{* *} p<.001$.

In Model 1, the Effortful Control construct was measured by Attention Focusing (AF), Inhibitory Control (IC), Activation Control (AC), and Low-Intensity Pleasure (LIP) scales. The small negative error variance for Activation Control, equal to -.084 (S.E. $=.092, p=.359)$, was constrained to be zero. The model with one error covariance, Inhibitory Control with Low-Intensity Pleasure, showed excellent fit: $\chi^{2}=1.43, d f=2, p=.49, \mathrm{CFI}=1.00$, RMSEA $=.000$. In Model 2, Effortful Control was measured by four latent constructs, AF, IC, AC, and LIP, depicted in Figure 1.

The measurement model for problem behaviour included two latent constructs: Internalising Problems were indicated by parent- and teacher-reported emotional symptoms and peer problems; Externalising Problems were indicated by parent- and teacher-reported conduct problems and hyperactivity. The bivariate correlations between parent-reported and teacher-reported Externalising problems, Internalising problems, and Total difficulties were $.50, .23$ and .41 , respectively. We used correlated errors among similar informants to model method variance. The fit indices indicated good model fit: $\chi^{2}=24.85, d f=9, p=.003$, $\mathrm{CFI}=.983, \mathrm{RMSEA}=.054$.

Academic achievement was measured as a latent variable with three indicators (Russian, math, and literature grades for the year). The subjective well-being construct was measured by self-reported items of the SLSS; the model with one error 
covariance between two negatively worded items also showed good fit: $\chi^{2}=29.65$, $d f=13, p=.005, \mathrm{CFI}=.971$, RMSEA $=.046$.

The structural models included paths from effortful control to internalising problems, externalising problems, subjective well-being, and academic achievement. Model 1 failed to yield a good fit $\left(\chi^{2}=545.88, d f=189, p<.001, \mathrm{CFI}=.847\right.$, RMSEA =.056). Therefore, correlated error was allowed between outcome latent constructs, among their indicators and between Inhibitory Control and Externalising Problems. The fit of the final Model 1 (Figure 2) was adequate: $\chi^{2}=474.40$, $d f=187, p<.001, \mathrm{CFI}=.908, \mathrm{RMSEA}=.050$. Higher effortful control was related to better academic achievement and subjective well-being, and fewer externalising and internalising problems, accounting for $11 \%, 2 \%, 29 \%$, and $16 \%$ of the variance, respectively.

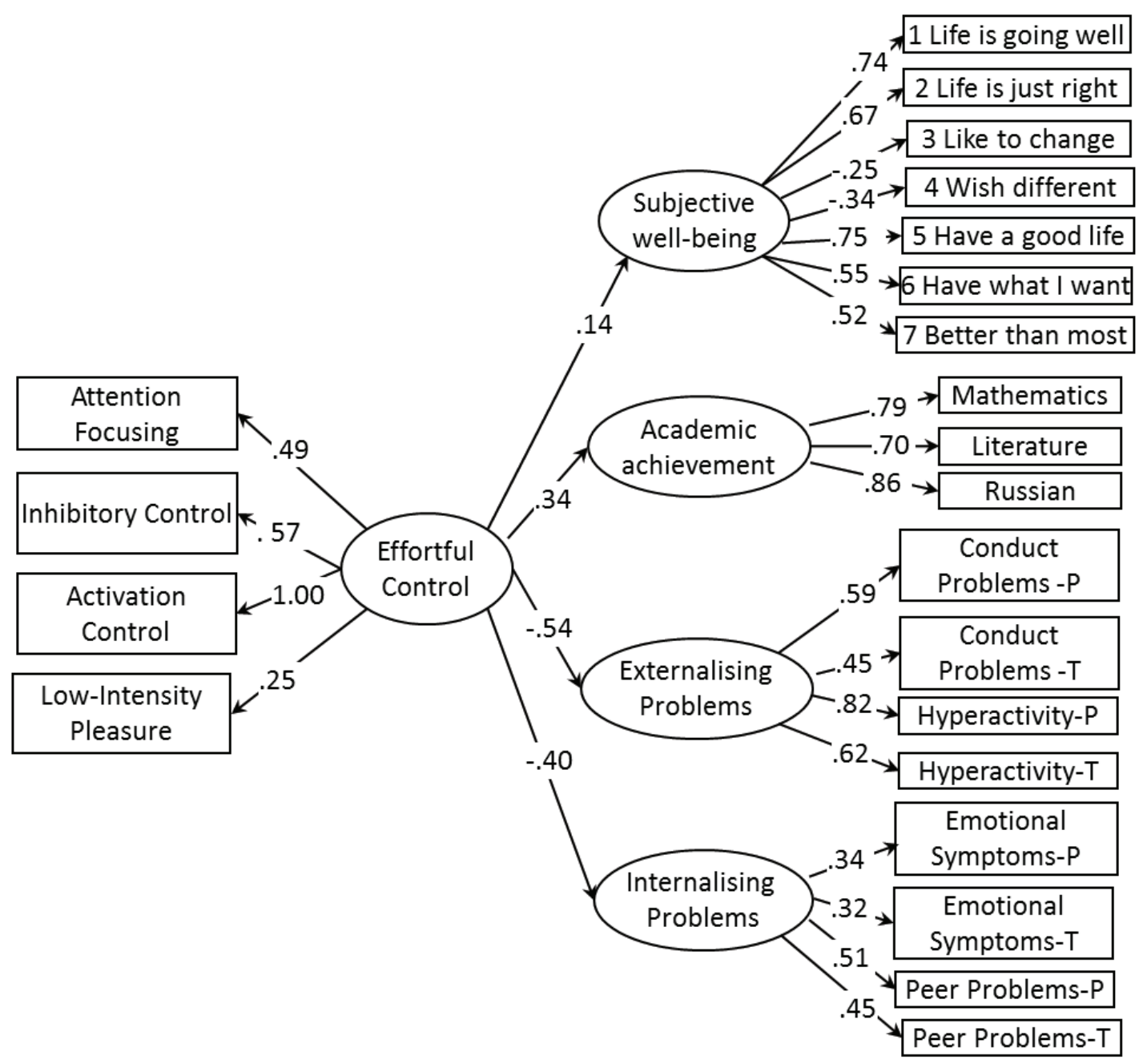

Figure 2. Structural model of effortful control predicting problem behaviour ( $\mathrm{P}=$ parent reports, $\mathrm{T}=$ teacher reports), academic achievement, and subjective well-being (selfreports).

Note. The coefficients are standardised loadings. For clarity, pathways that were not significant at $p<.05$ and correlated errors are not shown. 
Model 2, with insignificant paths removed (Figure 3), provided satisfactory fit to the data: $\chi^{2}=757.50, \mathrm{df}=384, \mathrm{p}<.001, \mathrm{CFI}=.903, \mathrm{RMSEA}=.040$. Higher attention focusing was related to better subjective well-being and fewer externalising and internalising problems; inhibitory control was negatively related to externalising problems, whereas activation control was positively associated with academic achievement. Together, the model explained $22 \%$ of the variance for academic achievement, $8 \%$ for subjective well-being, $69 \%$ for externalising problems, and $72 \%$ for internalising problems.

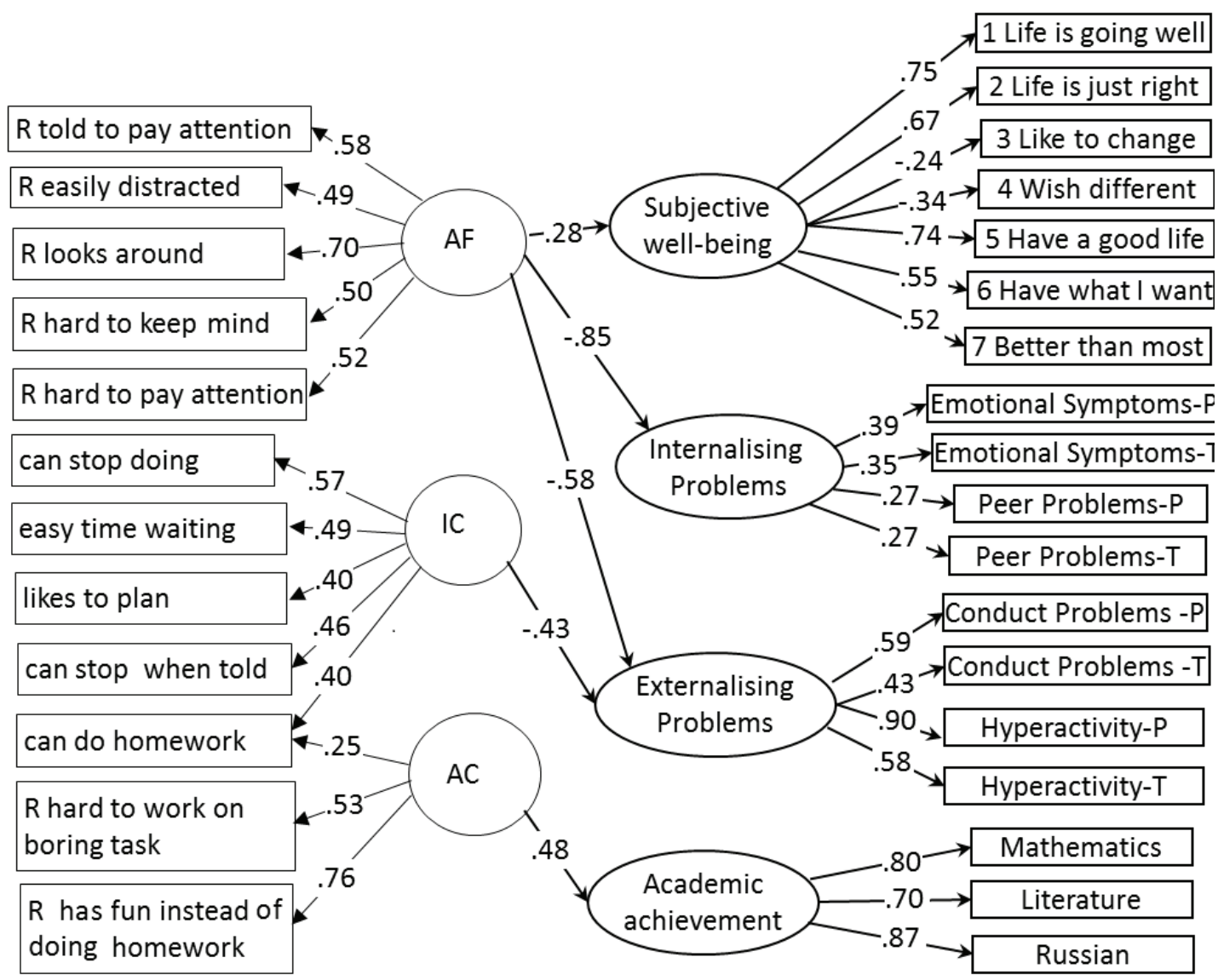

Figure 3. Structural model of Attention Focusing (AF), Inhibitory Control (IC), and Activation Control ( $\mathrm{AC})$ predicting problem behaviour $(\mathrm{P}=$ parent reports, $\mathrm{T}=$ teacher reports), academic achievement, and subjective well-being (self-reports).

Note. Values are standardised estimates $(p<.001)$. For clarity, covariances between AF, IC, and AC are not shown.

\section{Discussion}

The findings of this study supported the four-factor structure of the abbreviated TMCQ Effortful Control scale from the Temperament in Middle Childhood Questionnaire (TMCQ, Simonds \& Rothbart, 2004), including Attention Focusing, Inhibitory Control, Activation Control, and Low-Intensity Pleasure. The Russian version of the abbreviated TMCQ Effortful Control scale showed good convergent, discriminant, and concurrent validity, and adequate internal consistency and test- 
retest reliability. Thus, this instrument has satisfactory psychometric properties and may be used as a brief measure of child effortful control in large-scale studies, allowing cross-cultural comparisons and greater generalization of findings. Higher parent ratings for girls on effortful control and its components are largely consistent with the existing research on gender differences in temperament (Else-Quest et al., 2006). However, in contrast to Else-Quest et al's (2006) meta-analysis and recent TMCQ findings with Spanish children (Ato, Galián, \& Fernández-Vilar, 2014), there were no gender differences in inhibitory control in this study. Whether this discrepancy reflects cultural differences in gender differentiation or cultural bias in parent reports, remains to be investigated.

Showing that effortful control and its components were strongly related to personality traits, our results confirmed and extended previous findings (Halverson et al., 2003) to lower-order traits. The strongest links were found for conscientiousness and all traits from this domain, supporting a conceptual link between effortful control and conscientiousness (Eisenberg, Duckworth, Spinrad, \& Valiente, 2014) in the Russian cultural context. Relations between effortful control and agreeableness are also in line with previous findings from other samples. Positive association with the openness domain has been found in adolescents (Tackett, Kushner, De Fruyt, \& Mervielde, 2013) and may be due to the high covariation between conscientiousness and intellect at earlier ages (Tackett et al., 2012). Negative association between effortful control and negative affect have been repeatedly supported by other studies with Western and non-Western samples. The evidence on the relationship between effortful control and positive emotions is controversial (Eisenberg, Eggum, Vaughan, \& Edwards, 2010); however, positive correlation found in the present study, along with the link with subjective well-being, is consistent with the role of effortful control in subsequent life satisfaction (Moffitt et al., 2013). To our knowledge, this is the first study to show a positive association between effortful control and subjective well-being in childhood.

This study is also the first to examine simultaneously the effect of effortful control on three domains of child well-being - mental health, subjective well-being, and academic achievement - in structural equation models. The findings confirmed that higher effortful control was associated with lower levels of internalising and externalising problems (Eisenberg et al., 2010). In line with previous research, the links with externalising problems were somewhat stronger than with internalising problems (Caspi, Henry, McGee, Moffitt, \& Silva, 1995; Zhou, Lengua, \& Wang, 2009). This consistency in the pattern of results obtained in different parts of the world (North America, New Zealand, China, and Russia) suggests that the relationship between effortful control and two major groupings of problem behaviour - externalising and internalising - may be universal. Future studies using neuroimaging techniques should investigate how individual differences in the activity of brain regions involved in emotion and behaviour regulation are related to individual differences in questionnaire measure of effortful control that emerged from factor analytic studies of voluntary regulatory behaviours.

Our findings also confirmed the important role of effortful control in academic success, suggesting that activation control makes a major contribution. In our study, inhibitory control was not related to academic achievement in primary schoolchil- 
dren, consistent with the findings on math achievement of Spanish primary schoolchildren (Sánchez-Pérez et al., 2015). However, another study found that inhibitory control significantly predicted math achievement in Canadian 9-11-year-olds (Oberle \& Schonert-Reichl, 2013). More research is needed to clarify the role of each specific component of effortful control in child well-being and to understand the neural mechanisms involved. Our findings suggest that attentional control is important for problem behaviour and subjective well-being, whereas inhibitory control only contributed to externalising problems, and activation control only contributed to academic achievement.

\section{Conclusion}

This study showed that effortful control and its components were strongly related to personality traits and extended previous findings to lower-order traits. Our findings also confirmed the important role of effortful control in academic success and well-being of Russian primary schoolchildren. The findings in this study provided a strong basis for further investigation of the relations between effortful control on the one hand, and personality and well-being on the other, in primary schoolchildren from different cultures. It is also worth mentioning that interventions targeting effortful control may have major implications for child well-being by reducing problem behaviours and promoting academic achievement and life satisfaction. Overall, this study suggests that community-based programs developed in the West may improve child developmental outcomes in other cultural contexts.

\section{Limitations}

The present study has several limitations that should be addressed in future research. Firstly, the cross-sectional design did not allow consideration of causal influences; the findings should be supported by longitudinal data. Secondly, although reasonably large and diverse, the sample was not representative; to increase the validity of the findings, more elaborated sampling methods are needed. Thirdly, although three-informant data provided support for the links of effortful control with problem behaviour, subjective well-being, and academic achievement, the relationships of effortful control with personality traits might be partly due to shared method variance; the study would benefit from the inclusion of experimental and neurobiological measures.

\section{Acknowledgements}

The work on this manuscript was supported by the Russian Scientific Foundation \# 16-18-00003 (data collection and analyses) and the Russian Foundation for Basic Research \# 16-06-00022 (preparation of this manuscript). We thank the colleagues, participating parents, teachers, and the administrative authorities of the schools. 


\section{References}

Arbuckle, J.L. (2008). Amos 17.0 User's Guide. Chicago, IL: SPSS Inc.

Ato, E., Galián, M.D., \& Fernández-Vilar, M.A. (2014). Gender as predictor of social rejection: The mediating/moderating role of effortful control and parenting. Anales de Psicología, 30, 1069-1078. http://dx.doi.org/10.6018/analesps.30.3.193171

Caspi, A., \& Shiner, R.L. (2006). Personality development. In W. Damon, \& R. Lerner (Series Eds.) \& N. Eisenberg (Vol. Ed.), Handbook of child psychology, Vol. 3. Social, emotional, and personality development (6th edition, pp. 300-365). New York: Wiley.

Caspi, A., Henry, B., McGee, R.O., Moffitt, T.E., \& Silva, P.A. (1995). Temperamental origins of child and adolescent behavior problems: From age three to age fifteen. Child Development, 66, 55-68. http://dx.doi.org/10.1111/j.1467-8624.1995.tb00855.x

Digman, J.M., \& Shmelyov, A.G. (1996). The structure of temperament and personality in Russian children. Journal of Personality and Social Psychology, 71, 341. http://dx.doi. org/10.1037/0022-3514.71.2.341

Eisenberg, N., Duckworth, A.L., Spinrad, T.L., \& Valiente, C. (2014). Conscientiousness: Origins in childhood? Developmental Psychology, 50, 1331-1349. http://dx.doi.org/10.1037/ a0030977

Eisenberg, N., Eggum, N., Vaughan, J., \& Edwards, A. (2010). Relations of self-regulatory/control capacities to maladjustment, social competence, and emotionality. In R. Hoyle (Ed.). Handbook of personality and self-regulation (pp. 21-46). Oxford, England: Wiley-Blackwell. https://doi.org/10.1002/9781444318111.ch2

Eisenberg, N., Valiente, C., \& Eggum, N.D. (2010). Self-regulation and school readiness. Early Education and Development, 21(5), 681-698. http://dx.doi.org/10.1080/10409289.2010.49 7451

Else-Quest, N.M., Hyde, J.S., Goldsmith, H.H., \& Van Hulle, C.A. (2006). Gender differences in temperament: A meta-analysis. Psychological Bulletin, 132, 33-72. http://dx.doi. org/10.1037/0033-2909.132.1.33

Goodman, R. (2001). Psychometric properties of the Strengths and Difficulties Questionnaire (SDQ). Journal of the American Academy of Child and Adolescent Psychiatry, 40, 1337-1345. http://dx.doi.org/10.1097/00004583-200111000-00015

Goodman, R., \& Scott, S. (2012). Child and adolescent psychiatry. 3nd edition. Wiley-Blackwell. https://doi.org/10.1002/9781118340899

Goodman, R., Slobodskaya, H.R., \& Knyazev, G.G. (2005). Russian child mental health: A crosssectional study of prevalence and risk factors. European Child and Adolescent Psychiatry, 14, 28-33. http://dx.doi.org/10.1007/s00787-005-0420-8

Halverson, C.F., Havill, V.L., Deal, J., Baker, S.R., Victor, J.B., Pavlopoulos, V., ... Wen, L. (2003). Personality structure as derived from parental ratings of free descriptions of children: The Inventory of Child Individual Differences. Journal of Personality, 71, 995-1026. http:// dx.doi.org/10.1111/1467-6494.7106005

Huebner, E.S. (1991). Initial development of the Student's Life Satisfaction Scale. School Psychology International, 12, 231-240. http://dx.doi.org/10.1177/0143034391123010

Kohnstamm, G. A., Halverson, C. F., Jr., Mervielde, I., \& Havill, V. L. (1998). Parental descriptions of child personality: developmental antecedents of the Big Five? Mahwah, NJ: Lawrence Erlbaum Associates.

Kotelnikova, Y., Olino, T.M., Klein, D.N., Mackrell, S.V.M., \& Hayden, E.P. (2016). Higher- and lower-order factor analyses of the Temperament in Middle Childhood Questionnaire. Assessment, 24(8), 1-12. http://dx.doi.org/10.1177/1073191116639376 
Leto, I.V., Petrenko, E.N., \& Slobodskaya, H.R. (2018). Life satisfaction in Russian primary schoolchildren: links with personality and family environment. Journal of Happiness Studies. https://doi.org/10.1007/s10902-018-0036-6

Mary Rothbart's Temperament Questionnaires. Retrieved September 22, 2018. Available from https://research.bowdoin.edu/rothbart-temperament-questionnaires/

McClelland, M.M., Acock, A.C., \& Morrison, F.J. (2006). The impact of kindergarten learningrelated skills on academic trajectories at the end of elementary school. Early Childhood Research Quarterly, 21, 471-490. http://dx.doi.org/10.1016/j.ecresq.2006.09.003

Moffitt, T.E., Arseneault, L., Belsky, D., Dickson, N., Hancox, R.J., Harrington, ... Caspi, A. (2011). A gradient of childhood self-control predicts health, wealth, and public safety. Proceedings of the National Academy of Sciences, 108, 2693-2698. http://dx.doi.org/10.1073/ pnas. 1010076108

Moffitt, T.E., Poulton, R., \& Caspi, A. (2013). Lifelong impact of early self-control. American Scientist, 101(5), 352-359. http://dx.doi.org/10.1511/2013.104.352

Oberle, E., \& Schonert-Reichl, K.A. (2013). Relations among peer acceptance, inhibitory control, and math achievement in early adolescence. Journal of Applied Developmental Psychology, 34, 45-51. http://dx.doi.org/10.1016/j.appdev.2012.09.003

O'Hare, W.P., \& Gutierrez, F. (2012). The use of domains in constructing a comprehensive composite index of child well-being. Child Indicators Research, 5, 609-629. https://doi. org/10.1007/s12187-012-9138-6

Proctor, C. L., Linley, P. A., \& Maltby, J. (2009). Youth life satisfaction: A review of the literature. Journal of Happiness Studies, 10, 583-630. http://dx.doi.org/10.1007/s10902-008-9110-9

Putnam, S.P., Ellis, L.K., \& Rothbart, M.K. (2001). The structure of temperament from infancy through adolescence. In A. Eliasz \& A. Angleitner (Eds.), Advances/proceedings in research on temperament (pp. 165-182). Lengerich, Germany: Pabst Scientist.

Rees, G., Goswami, H., Pople, L., Bradshaw, J., Keung, A., \& Main, G. (2012). The good childhood report 2012: A review of our children's well-being. London: The Children's Society.

Rothbart, M.K. (2007). Temperament, development, and personality. Current Directions in Psychological Science, 16, 207-212. http://dx.doi.org/10.1111/j.1467-8721.2007.00505.x

Rothbart, M.K., Ahadi, S.A., \& Evans, D.E. (2000). Temperament and personality: Origins and outcomes. Journal of Personality and Social Psychology, 55, 958-966. http://dx.doi. org/10.1037/0022-3514.78.1.122

Rothbart, M.K., Sheese, B.E., Rueda, M.R., \& Posner, M.I. (2011). Developing mechanisms of self-regulation in early life. Emotion Review, 3, 207-213. http://dx.doi. org/10.1177/1754073910387943

Sánchez-Pérez, N., Fuentes, L.J., Pina, V., López-López, J.A., \& González-Salinas, C. (2015). How do different components of Effortful Control contribute to children's mathematics achievement? Frontiers in Psychology: Educational Psychology, 6, 1383. http://dx.doi.org/10.3389/ fpsyg.2015.01383

Simonds, J., Kieras, J., Rueda, M., \& Rothbart, M. (2007). Effortful control, executive attention, and emotional regulation in 7-10-year-old children. Cognitive Development, 22, 474-488. http://dx.doi.org/10.1016/j.cogdev.2007.08.009

Simonds, J., \& Rothbart, M.K. (2004). The Temperament in Middle Childhood Questionnaire (TMCQ): A computerized self-report measure of temperament for ages 7-10. Poster presented at the Occasional Temperament Conference, Athens, GA.

Shiner, R.L., \& DeYoung, C.G. (2013). The structure of temperament and personality traits: A developmental perspective. In P. Zelazo (Ed.), Oxford handbook of developmental psychology (pp. 113-141). New York: Oxford University Press. 
Slobodskaya, H.R., \& Zupančič, M. (2010). Development and validation of the Inventory of Child Individual Differences-Short Version in two Slavic countries. Studia Psychologica, 52, 23-39.

Tackett, J.L., Slobodskaya, H.R., Mar, R.A., Deal, J., Halverson, C.F., Baker, S.R., ... Besevegis, E. (2012). The hierarchical structure of childhood personality in five countries: Continuity from early childhood to early adolescence. Journal of Personality, 80, 847-879. https://doi. org/10.1111/j.1467-6494.2011.00748.x

Tackett, J.L., Kushner, S.C., De Fruyt, F., \& Mervielde, I. (2013). Delineating personality traits in childhood and adolescence: associations across measures, temperament, and behavioral problems. Assessment, 20, 738-751. http://dx.doi.org/10.1177/1073191113509686

Zhou, Q., Lengua, L.J., \& Wang, Y. (2009). The relations of temperament reactivity and effortful control to children's adjustment problems in China and the United States. Developmental Psychology, 45, 724-739. http://dx.doi.org/10.1037/a0013776

Original manuscript received January 12, 2018 Revised manuscript accepted September 13, 2018 First published online December 20, 2018 